\title{
CONVERSANDO COM AS DORES CRÔNICAS: SOBRE SUGESTÕES HIPNÓTICAS E NÍVEIS DE EXPERIÊNCIA VIVIDA $^{1}$
}

\author{
CONVERSING WITH CHRONIC PAIN: ON HYPNOTIC SUGGESTIONS AND LEVELS OF LIVING \\ EXPERIENCE
}

CONVERSANDO CON LOS DOLORES CRÓNICOS: SOBRE SUGESTIONES HIPNÓTICAS Y
NIVELES DE EXPERIENCIA VIVIDA

Mauricio da Silva Neubern*

\begin{abstract}
RESUMO
Este trabalho busca tecer uma compreensão inicial, em termos clínicos e teóricos, das relações entre os tipos de sugestóes hipnóticas e os níveis de experiência vivida de pessoas com dores crônicas. Partindo de duas breves ilustrações clínicas, propõe relações entre os tipos de sugestões que se utilizam dos signos semióticos ícones, índices e símbolos, relacionando-os aos níveis de experiência vivida da pessoa, seja ela vital ou subjetiva. Destaca que, ao mesmo tempo em que as sugestóes sempre podem envolver os três tipos de signos, elas podem enfatizar preferencialmente aqueles que melhor se endereçam a determinado nível de experiência vivida. $\mathrm{O}$ artigo se conclui ressaltando que a relação entre sugestões hipnóticas e níveis de experiência deve ser concebida numa perspectiva ampla de subjetividade, incluindo principalmente a dimensão do sujeito e suas diferentes formas de autonomia.
\end{abstract}

Palavras-Chave: Hipnose. Dores crônicas. Signos. Experiência vivida.

\begin{abstract}
This article interweaves basic clinical and theoretical understandings of the relationships between types of hypnotic suggestions and the levels of living experiences described by people with chronic pain. Based on two brief clinical examples, it proposes relationships between the types of suggestions that use the semiotic signs of icons, indexes, and symbols, and relates them to the levels of vital and subjective experience. It is important to note that, while the suggestions can always involve all three types of signs, they can
\end{abstract}

\footnotetext{
Texto recebido em 30 de setembro de 2013 e aprovado para publicação em 25 de março de 2015.

1 O presente trabalho é fruto do projeto "Hipnose, Dor e Subjetividade: Construindo o Contexto Terapêutico", coordenado por seu autor. Tal projeto foi aprovado pelo Comitê de Ética da UnB e as condições éticas para pesquisa com sujeitos humanos foram rigorosamente obedecidas, a começar pela assinatura do Termo de Consentimento Livre e Esclarecido. Agradecimentos ao Centro de Atendimentos e Estudos Psicológicos (CAEP), do Instituto de Psicologia (IP/UnB).

Doutor em Psicologia; professor adjunto no Instituto de Psicologia (IP) da Universidade de Brasília (UnB). Endereço: Campus Darcy Ribeiro, ICC Sul, Instituto de Psicologia, Departamento de Psicologia Clínica. Brasília-DF, Brasil. CEP: 70910-900.

E-mail: mauricio.neubern@gmail.com. Telefone (61) 3107-6890.
} 
preferentially emphasize those that best address a specific level of living experience. In its conclusion, the article emphasizes that the relationship between hypnotic suggestions and levels of experience should be approached from a perspective of ample subjectivity, especially including the dimension of the subject and its different manners of autonomy.

Keywords: Hypnosis. Chronic pain. Signs. Lived experience.

\section{RESUMEN}

Este trabajo busca establecer una comprensión inicial, en términos clínicos y teóricos, de las relaciones entre los tipos de sugestiones hipnóticas y los niveles de experiencia vivida de personas con dolores crónicos. Partiendo de dos breves ilustraciones clínicas, propone relaciones entre los tipos de sugestiones que utilizan signos semióticos íconos, índices y símbolos relacionándolos con los niveles de experiencia vivida de la persona, sea ella vital o subjetiva. Destaca que, al mismo tiempo en que las sugestiones siempre pueden involucrar a los tres tipos de signos, ellas pueden enfatizar preferencialmente aquellos que mejor se dirigen a un a determinado nivel de experiencia vivida. El artículo concluye resaltando que la relación entre sugestiones hipnóticas y niveles de experiencia debe ser concebida en una perspectiva amplia de subjetividad, incluyendo principalmente la dimensión del sujeto y sus diferentes formas de autonomía.

Palabras clave: Hipnosis. Dolores crónicos. Signos. Experiencia vivida.

\section{INTRODUÇÃO}

retomada do interesse pela hipnose nas últimas décadas, em diferentes
centros internacionais (Celestin-Lhopiteau, 2012; Jensen, 2010), permite
conceber que, malgrado sua comprovada eficácia (Goldstein, 2011; Jensen \& Patterson, 2014), a reflexão teórica sobre o assunto não parece ser priorizada por seus pesquisadores. O papel que a sugestão hipnótica desempenha, aí envolvendo temas como sua forma de produção na linguagem, a maneira de desencadear processos inconscientes, sua qualificação na relação entre os protagonistas, parecem ser pouco interessantes para a grande maioria das pesquisas, cuja ênfase geralmente recai sobre avaliação de eficácia (Dillworth \& Jensen, 2010), efeitos em populações e problemas específicos (Abrahamsen, Baad-Hansen, Zachariae, \& Svensson, 2011; Teeley et al., 2012) ou os processos neurológicos do transe (Kirjanen, 2012; Vaitl, 2010). Assim, embora haja esforços de discussão em termos qualitativos (Michaux, 2007; Roustang, 2006) e medidas sensíveis aos aspectos qualitativos das dores crônicas (World Health Organisation [WHO], 2014), estes permanecem isolados, seja por não favorecerem uma continuidade 
em sua produção acadêmica, de modo a conseguirem espaços institucionais significativos (como linhas de pesquisa, financiamento, núcleos e laboratórios), seja por se constituírem minoritários frente à considerável produção quantitativa, com grande ênfase biomédica e instrumentalista (Neubern, 2012; Portaria $n^{\circ}$ $1.083,2012)$.

Desse modo, diante de semelhante cenário, o problema do uso da sugestão se vê largamente limitado em termos clínicos (Neubern, 2013), tanto no que se refere à pesquisa como no tocante à intervenção. É possível conceber que a ausência quase que completa de uma reflexão conceitual mais ampla e consistente não permita ao pesquisador considerar com maior precisão problemas ligados à complexa realidade das dores crônicas e da própria construção do transe. Temas como violência, papéis familiares, sexualidade, estigma social, perda financeira, gênero, isolamento, falta de acolhimento nos serviços de saúde, ruptura de projetos de vida e espiritualidade são muito comuns na experiência de tais pessoas (Breton, 2012), o que leva a conceber que o que vivenciam com suas dores não consiste em entidades reificadas, capazes de emitir respostas unívocas a serem relacionadas numa lógica estatística. Trata-se muito mais de sistemas complexos que articulam diversas dimensóes socioculturais e incluem o corpo como um de seus principais territórios de subjetivação e experiência vivida. Ao mesmo tempo, essa ausência conceitual também dificulta a compreensão dos processos vividos da corporeidade que remetem a uma dimensão vital da experiência de dor relacionada a toda uma herança filo e ontogenética (Cyrulnik, 2001; Morin, 2001; Stern, 2010). Tal dimensão frequentemente aparece descrita pelas pessoas por termos reativos (esquenta, puxa, fura, aperta, corta) associada a noções como energia, irradiação e ciclos e parece remeter a complexos sistemas que não se restringem à lógica dominante dos padrões regulares.

Assim, diante de tal cenário e não dispondo de uma constelação de conceitos que lhe permita a investigação, o pesquisador se coloca diante de um considerável problema no que diz respeito à construção, reflexão e utilização das sugestões hipnóticas. Ele talvez possa compreender, por meio de seu treinamento, a importância de certas figuras de linguagem, como a metáfora (Brugnoli, 2014; Celestin-Lhopiteau, 2011), mas dificilmente pode conceber para onde direcionála com maior precisão, no caso daquela pessoa em particular, por não conceber conceitualmente onde e como se articulam, em sua experiência, processos como o desemprego, o mandato familiar de provedora, a mudança radical em sua sexualidade e as exigências relativas à sua feminilidade. Menos ainda seria capaz de conceber como tais processos de simbolização se articulam com os complexos processos vitais de sua corporeidade, em que a mastectomia lhe traz dores profundas, que parecem queimar, rasgar e perfurar a região afetada pela cirurgia. 
Desse modo, ao mesmo tempo em que a intervenção pode ser comprometida pela ausência da produção conceitual, não possibilitando maior precisão técnica, a reflexão típica da pesquisa não concretiza avanços, uma vez que não consegue qualificar as relações com o empírico nem promover o necessário refinamento conceitual para sua continuidade (Rey, 2011).

Assim, este trabalho busca tecer ideias iniciais de uma compreensão teórica e clínica sobre as relações entre os tipos de sugestôes hipnóticas e os diferentes níveis de experiência de dores crônicas. Com base em duas breves ilustrações clínicas, inspiradas na hipnose de Milton Erickson (Erickson \& Rossi, 1979; Erickson, 1983), será desenvolvida uma relação entre as sugestões hipnóticas, aqui tomadas de um ponto de vista semiótico (Peirce, 1998b) e os diferentes níveis de experiências vividas das dores crônicas, aqui concebidas numa ótica complexa como processos subjetivos e vitais (Morin, 2001; Neubern, 2013; 2014). Nesta proposta, compreende-se que, mesmo que não seja coerente a busca de uma relação linear entre tais processos, é possível se conceber que determinados usos de sugestão podem privilegiar certos níveis de experiências de dores crônicas, uma vez que as sugestôes promovem nelas um processo de reconfiguração que obedecem à condição autorregulada dos sistemas que as caracterizam.

Cabe acrescentar ainda que, por se tratar de um estudo teórico e clínico, as discussões serão desenvolvidas em termos de ilustrações clínicas e não propriamente de estudos de caso. Dito de outro modo, por limites diversos, não se torna possível demonstrar o passo a passo da construção das informações da pesquisa, mas apenas apontar caminhos entre as sugestóes tomadas como processos semióticos e a experiência de tais pessoas. Contudo vale acrescentar que a base metodológica aqui desenvolvida remete a uma concepção construtivointerpretativa (Rey, 2005) em que as informações empíricas são qualificadas em razão do valor heurístico que têm para a construção do pensamento do pesquisador.

\section{SEMIÓTICA, CLÍNICA \& COMPLEXIDADE}

A proposta aqui concebida analogicamente de se conversar com as dores crônicas não consiste numa conversa racional e linear com o corpo, como se suas partes, tomadas de modo antropomórfico, pudessem compreender o que se diz a elas e obedecer a comandos verbais. Concebe-se, ao contrário, que as sugestões hipnóticas podem, dentro de certos parâmetros, acessar e promover a reconfiguração de processos de dores crônicas que se organizam em níveis específicos de experiência, que podem ser tanto o nível vital marcado pela dinâmica vivida de cunho biológico como o nível subjetivo, no qual se 
configuram as influências de diversas dimensões socioculturais (Neubern, 2013; 2014). No primeiro nível, os sistemas de configuraçôes são vitais e envolvem processos sensórios, automatismos, circuitos de reaçôes, emoçôes e referem-se a toda uma gama de processos de herança filogenética típicas da espécie humana (Morin, 2001; 2005). Já o segundo nível remete à subjetivação oriunda da dialética do sujeito com o mundo (Rey, 2011), mais propriamente envolvendo a simbolização de dimensões familiares, sociais, econômicas, sexuais, gênero, espirituais, entre outras, que se constituem como fundamentais para a produção de sentidos em sua experiência de dores crônicas (Breton, 2012).

Tais concepções têm dois desdobramentos centrais. O primeiro deles é a organização configuracional dessas experiências (Neubern, 2010, 2013, 2014), ou seja, de sistemas que organizam tais processos e produzem, em sua dinâmica, qualidades dominantes de grande pertinência para o que é vivenciado pelo sujeito. Logo, embora na prática haja uma articulação estreita entre o vivido e o subjetivo, ambos obedecem a lógicas distintas que precisam ser consideradas em suas particularidades para fins terapêuticos. Assim, a vergonha das origens que uma pessoa tenha sobre si, como sentido subjetivo, ${ }^{2}$ e que se amplifica com seu diagnóstico de câncer, por exemplo, pode se encontrar atrelada às sensaçóes dominantes de queimadura, perfuração e corte do tumor, mas não deixa de ter uma lógica distinta dessas sensaçôes em termos de sua constituição e de sua dinâmica. Isso porque tal sentido de vergonha remete à produção simbólica referente, por exemplo, a processos históricos dessa pessoa, a todo um jogo social de classes sociais e raça que culminam com a exclusão perpassada por uma construção identitária ligada a um lugar inferior naquela sociedade, enquanto as sensações aqui descritas remetem a uma lógica de organização da própria dinâmica biológica do sujeito. Isso não permite conceber, entretanto, que o corpo também não seja perpassado e constituído simbolicamente, como destacado por importantes autores (Johnson, 2007; Merleau-Ponty, 2008), nem que processos de origem biológica, como as emoções, não tenham um papel central na construção dos sentidos subjetivos (Rey, 2011), mas apenas que tais níveis obedecem a lógicas diferenciadas e não têm uma relação linear e causal entre si.

O segundo deles é exatamente conceber uma leitura semiótica (Peirce, 1998a) das sugestões hipnóticas, que se constituem em proposições formadas por diferentes tipos de signos que, quando emitidos numa relação, podem fazer com que o paciente rompa momentaneamente um conjunto de referências eu-mundo (que situam o sujeito no corpo vivido no tempo, espaço, causa e matéria), mergulhando num estado de transe. Esses signos são classificados

Sentidos subjetivos são as qualidades dominantes das configuraçôes subjetivas (Rey, 2011; Neubern, 2010). Articulam, ao mesmo tempo, processos simbólicos e emocionais baseados no jogo dialético do sujeito com seus diferentes momentos de inserção no mundo sociocultural. 
em três tipos que remetem a suas respectivas dimensões de experiência, ${ }^{3}$ que também envolvem, a bem dizer, lógicas específicas (Peirce, 1998a). O terceiro e mais elaborado, típico da linguagem, é a produção simbólica, que consiste no uso das palavras e proposiçôes em geral (trata-se do nível do pensar como mediação). Não raro os pacientes com dores crônicas têm verdadeiras teorias sobre sua condição (punição divina, injustiça da vida, sacrifício pela família), que se constituem como produções simbólicas centrais em sua experiência. $\mathrm{O}$ segundo, ligado a uma lógica de reação entre elementos distintos (reagir), são os indices e consistem em sinais que fixam a atenção do sujeito, que apontam para algo mais, numa sequência significativa para a pessoa. É o caso, por exemplo, das pontadas que uma pessoa pode sentir, como sinal de uma dor que se aproxima; ele implica o sujeito numa reação, indica-lhe algo, mas não necessariamente uma simbolização. E o primeiro, mais ligado à ideia de uma "primeiridade" anterior ao pensamento e à deliberação (sentir) que se experimenta sem refletir sobre si mesma, são os ícones que se relacionam ao objeto representado por analogia, como no caso das imagens que uma pessoa pode desenvolver, no transe, para representar suas dores crônicas.

Quando um clínico profere sugestões hipnóticas, os signos referem-se a algum objeto e evocam alguma experiência (interpretante) no paciente que a recebe. $\mathrm{Na}$ experiência dessa pessoa podem emergir diferentes tipos de interpretantes, como o sentir-se absorto numa paisagem sem nada pensar ("primeiridade"), a interferência de algo que anestesia a sequência automática criada pelos índices de dor ("segundidade") ou ainda uma nova forma de pensar simbolicamente as relações de exploração às quais se vê submetida ("terceiridade"). É isso que permite conceber, como hipótese diretriz deste estudo, que, apesar de o nível dos simbolos ser o dominante na linguagem ordinária e na hipnótica, e apesar de uma sentença poder conter diferentes tipos de signos, torna-se possível privilegiar dimensões específicas de dores crônicas em termos vividos e subjetivos, conforme acima explicados.

\section{ILUSTRAÇÕES CLÍNICAS}

\section{José Antônio, 65 anos}

José Antônio, 65 anos, tinha dores intensas nas regiões do quadril, do alto da coluna e do pescoço em decorrência de uma cirurgia para extração de um tumor e de um acidente automobilístico. Estava deprimido, com sintomas

\footnotetext{
Para Peirce (1998a), os signos, estruturas que representam ou substituem algo, remetem a respectivos tipos de experiência humana: ícones - "primeiridade" (sensação primeira das coisas, sentir); índices - "segundidade" (reação, confronto entre dois elementos); símbolos - "terceiridade" (mediar ou pensar). No entanto, para efeito deste trabalho, buscou-se uma relação com as perspectivas complexas (Morin, 2001; Neubern, 2014), em que a experiência, inclusive como interpretantes, são organizadas em sistemas de processos semióticos presentes nas diferentes ações humanas.
} 
de pânico e relutante quanto à ideia de retomar sua fisioterapia e seguir as recomendações médicas. Tais dores, que, segundo ele, repuxavam, apertavam e prendiam, faziam com que seus movimentos físicos fossem restritos de diferentes formas: sua cabeça não conseguia girar normalmente para os lados nem olhar para cima, o que o levava a fixar seu olhar apenas para o lado direito e para baixo; seus movimentos de rotação do quadril e torção da coluna encontravamse debilitados e restritos, enrijecendo sua coluna; e seus passos, com um campo restrito de possibilidades, faziam com que seus movimentos fossem curtos e seu andar de equilíbrio precário, levando-o algumas vezes a perigosas quedas. No processo hipnótico, o pesquisador se utilizou de determinados tipos de sugestôes hipnóticas tais como as expostas a seguir:

E, enquanto eu falo com você, eu fico me perguntando sobre como eram suas brincadeiras no rio, com as outras crianças... Como você pulava na água, pegava peixinhos... e depois se deitava ao sol quente para se secar. [...] Como era bom poder sentir o corpo secando, o corpo relaxado e a alegria de estar ali, na fazenda [...], e depois correr de novo, montar no cavalo, subir nas árvores, comer fruta no pé.

É curioso notar que, durante tais sugestôes, que eram intensamente vividas pelo paciente, com relatos de fortes imagens e sensações corporais, José Antônio apresentou duas características distintas ao longo dos três meses de sessóes semanais de terapia. Em primeiro lugar, transpirou em abundância, molhando sua roupa e a própria poltrona onde estava sentado. Apesar de, curiosamente, a temperatura da sala parecer ter aumentado de modo nítido, como o próprio pesquisador atestou, o suor parecia coincidir com uma forte sensação por ele relatada de conforto e alívio quanto a suas dores, o que não experimentava há muito tempo. Em segundo lugar, após sentir esse alívio nada desprezível em diferentes partes do corpo, José Antônio pôde efetuar, mesmo em transe, uma série de movimentos, antes impedidos pelo repuxar e apertar de suas dores crônicas. Pôde se levantar e agachar, olhar em diferentes ângulos, virar o corpo para ambos os lados e dar passos num espectro de alcance muito maior do que o condicionado pelas dores no estado de vigília. Em três meses de processo terapêutico seguindo esse estilo de sugestões as dores antes por ele avaliadas como estando no nível 7 foram reduzidas para 2 ou 1, e José Antônio recobrou os movimentos, retomou os tratamentos e saiu do estado de depressão.

\section{Severino Silva, 67 anos}

Severino chegou à terapia apresentando dores de coluna muito intensas, originárias de uma queda. Altamente deprimido, chegando a manifestar ideias 
suicidas, Severino dizia que suas dores haviam aliviado muito pela hipnose, mas ainda se sentia mal consigo mesmo. ${ }^{4}$ Era uma pessoa generosa, sempre buscava auxiliar os outros e, desse modo, facilmente caía no papel de vítima de pessoas que o exploravam em termos emocionais e financeiros. Malgrado seu sucesso como empresário, não reconhecia suas vitórias nem o impacto destas em seu meio social: era, com frequência, convidado por pessoas eminentes para dar palestras e consultorias. Não gostava de comentar suas origens sertanejas e nordestinas, e se apercebeu, durante a terapia, que sentia vergonha de suas próprias raízes. Havia se acostumado a ter o tom de voz baixo e falho, a cabeça rebaixada e a coluna recurvada para frente, principalmente quando estava diante de alguém que considerava ser superior. Desse modo, o tipo de sugestôes hipnóticas utilizado durante essa fase de sua terapia era como ilustrado a seguir:

E fico me perguntando como será que aquele menino pobre, na Paraíba, conhecia tanto de cabras, vacas, cavalos... sabia como eram, do que precisavam... como cuidar deles [...] e era um bom negociador... sabia vender, trocar, fazer boas trocas pra sua família na feira [...] aquela vaca malhada que conseguiu vender bem [...], trocar por alguns jegues [...] e aprender a ler e escrever com 19 anos [...], mesmo com tantas pessoas dizendo que não tinha jeito [...] e se você visse esse menino agora, fico me perguntando o que você diria pra ele e que conselhos você gostaria de dar pra ele [...] e também fico me perguntando sobre como pode um grande homem ter sido um dia um menino esperto, arteiro, [...] às vezes pode parecer difícil entender como homens eminentes podem ter sido crianças um dia [...] e uma parte de sua mente pode ficar aqui pensando nisso, com tranquilidade [...] enquanto a outra pode ficar lá na feira, sentindo os cheiros da feira [...] vendo seus animais, mercadorias, homens... indo e vindo.

$\mathrm{Na}$ sequência deste trabalho de sessões semanais, Severino relatou que, espontaneamente, brotavam fragmentos de ideias que o levavam a repensar sua história. Era como se alguém conversasse com ele, inspirando-o a pensar de outra forma. Passou a contar histórias sobre suas leituras de cultura sertaneja (repentistas, cangaceiros, boiadeiros) e como isso tinha se tornado agradável. Seu humor havia melhorado de forma considerável, principalmente usando "seu jeito paraibano de ser" como forma de criar situações jocosas entre colegas e familiares, tornando-se um bom contador de histórias e piadas tipicamente nordestinas. De modo similar, suas formas de relação com os outros passaram a ser mais assertivas, sobretudo no sentido de não se submeter a exploraçôes e a se impor em situações que fossem de seu interesse. Seu tom de voz, sua cabeça erguida e sua coluna ereta, com a leveza de seu modo de se relacionar, indicavam

\footnotetext{
É importante destacar que, quando o paciente com dores crônicas está deprimido, comumente se torna necessário que esse problema seja trabalhado para que o tratamento geral seja bem-sucedido. A depressão pode favorecer a piora do quadro tanto por dificultar a adesão ao tratamento como por afetar o sistema imunológico e a própria corporeidade do sujeito, que pode se tornar mais tensa, pesada e dolorida.
} 
uma melhora acentuada em relação a si mesmo e, após um ano de terapia, o paciente recebia sua alta.

\section{DISCUSSÕES CLÍNICAS}

É importante destacar, a princípio, que, durante uma única indução hipnótica, costuma haver vários tipos de signos nas sugestões que trabalham sobre diferentes tipos de experiência, como pode ser notado, por exemplo, nas sessões de hipnoterapia aplicadas a dores crônicas e a diversas demandas clínicas (Celestin-Lhopiteau, 2011; Erickson \& Rossi, 1979; Neubern, 2014). No entanto, também é possível demonstrar que determinados trechos de sugestões, como os aqui ilustrados, proporcionam um trabalho de intervenção mais voltado para determinados níveis de experiências vividas, focando suas intervenções sobre configurações específicas ligados aos complexos sistemas que compõem as experiências de dores crônicas. Essa possibilidade de foco, ao mesmo tempo em que considera e ativa a dimensão autorreguladora de semelhantes sistemas, também permite um estabelecimento mais claro de metas terapêuticas de grande relevância para o trabalho com esse tipo de demanda.

Assim, no caso do sr. José Antônio, é possível conceber que esse conjunto de sugestôes atuou de maneira diversificada, evocando no paciente diferentes tipos de interpretantes. Por um lado, sentenças como "eu fico me perguntando como eram suas brincadeiras" abriram um largo espaço para que o sujeito acessasse um conjunto de processos subjetivos de "terceiridade" de grande valor terapêutico, uma vez que essa generalidade indica para o sujeito um leque de interpretantes possíveis como esses "brincadeiras pertencem a seu mundo, estão aprendidas e gravadas em você, são construtivas, podem ser acessadas por você”, por outro, não deixaram de promover, nesse processo autorregulado, a produção de imagens e sensaçôes, cuja vivência de "primeiridade" e "segundidade" tem grande impacto emocional e corpóreo sobre o próprio paciente.

A relevância terapêutica de tal processo pode ser destacada em diferentes níveis, mas também é marcante no que se refere ao nível vital. De fato, seria possível uma discussão ampla sobre seu impacto em termos de autoimagem ${ }^{5}$ (Gallagher \& Zahavi, 2008), onde reinam os simbolos, reconectando o sujeito com seu próprio ethos ou no tocante ao quadro de depressão ali presente, em que a pessoa mergulha numa experiência construtiva e agradável de maneira a não se conectar nem se sentir invadida por crenças e ideias negativas. No entanto o impacto dessas imagens e desse calor coincidiram com a retomada

\footnotetext{
O termo original em inglês é body-image. Refere-se ao sistema de experiências, atitudes e crenças sobre seu próprio corpo. Preferiu-se a tradução por autoimagem, em função das diferenças de significado entre a palavra corpo entre a língua inglesa e a língua portuguesa.
} 
de movimentos e posturas até então inibidos por suas dores, o que se iniciou no transe e, posteriormente, manteve-se no seu cotidiano. De um ponto de vista configuracional, tal processo de mudança pode ser compreendido da seguinte forma. Grande parte das potencialidades do conjunto sistêmico de forças ligado às regiōes afetadas encontrava-se inibida por influência das dores crônicas que castigavam o paciente, de maneira que a amplitude de alcance dos movimentos potenciais achava-se restrita a ponto de oferecer ao sujeito poucas opções de movimento da cabeça, do tronco, da cintura e, em consequência, das pernas. O impacto emocional ligado a tais imagens (Neubern, 2013), como o calor emergente em tal experiência, não consistiram na inclusão de elementos novos para o esquema corporal ${ }^{6}$ (Gallagher \& Zahavi, 2008) debilitado de movimentos, mas na evocação de aprendizados anteriores (também organizados como configuraçôes) que se encontravam inibidos nos sistemas nos quais as dores crônicas imperavam. Semelhante reorganização produziu novas resultantes, ou seja, novos vetores (índices) para movimento e postura cuja totalidade compõe novos e mais amplos campos de possibilidade para focar a cabeça, girar o tronco e o quadril, como ainda mover as pernas de forma equilibrada durante o caminhar. Poder mover a cabeça de um lado para o outro, para cima e para baixo, rodar o quadril em ângulos maiores para direita e esquerda, como ainda poder abrir melhor a perna e pisar com mais firmeza equilibrando a coluna significam para o sujeito, nesse nível de experiência, índices que apontam para uma reorganização dos sistemas e esquemas corporais que os antecedem.

Esse nível tipicamente reativo da "segundidade" (Peirce, 1998b) produz significados específicos em termos semióticos, os índices, que não mais se restringem a postura e movimento: eles implicam a dimensão animal, sensível e instintiva do comportamento humano, marcado pelo aprendizado individual e as necessidades da espécie. Nesse sentido, é possível conceber que o impacto das sugestôes não se volta mais sobre as resultantes das configuraçôes em termos de postura e movimento, mas para a própria sequência vivida de reaçôes (índices) mútuas dos complexos sistemas configuracionais que compóem o esquema corporal do paciente. Num contexto dissociado, agradável e protegido, típico desse tipo de intervenção (Erickson, 1983), o sujeito parece ter a possibilidade de focar sua atenção, de forma diferente da habitual, sobre determinadas regiōes e observar suas consequências de maneira que observar, focar, relaxar, compartimentalizar partes do corpo, ou seja, ações que reagem (como índices) sobre diferentes momentos de seu esquema corporal. Isso implica tanto na modificação da relação do sujeito quanto à experiência de dor crônica (uma vez que ele passa a influenciá-la em vez de apenas se sentir engolido ou paralisado

Esquema corporal refere-se ao sistema de processos que regulam postura e movimento corporais na ação intencional, implicando um nível pré-reflexivo (inconsciente na perspectiva aqui adotada) da consciência corporal. 
por ela), como na possibilidade de desencadear pequenas modificações na sequência dos circuitos reativos e automatizados do esquema que transformam suas configurações em alguma medida e, de fato, conseguem trazer algum alívio para o paciente.

Já no que diz respeito à experiência subjetiva, com a riqueza de sua produção de sentidos e interpretação do mundo, há toda uma dimensão simbólica de alta relevância para a abordagem das dores crônicas que se liga tanto às produções subjetivas do sujeito quanto a si mesmo, como suas formas de relação com as demais pessoas, tal como observado no caso do sr. Severino Silva. Mesmo que não se conceba uma relação linear entre esse nível de experiência e os demais em que as dores crônicas se configuram, é possível considerar que a influência que este nível exerce pode ser decisiva num processo terapêutico que busca promover a reconfiguração de tais experiências. Isso porque, além de questões como imunidade e vinculação ao tratamento, é possível conceber a existência de distintas maneiras, pelas quais as produções subjetivas negativas a respeito de si e determinados modos de relação com o outro podem impactar negativamente as dores crônicas de uma pessoa (Neubern, 2010; 2014). Certas formas de relacionamento, inclusive ligados à intimidade, podem desencadear facilmente os gatilhos de determinados esquemas corporais de uma dor específica, assim como sentidos subjetivos ligados à autodepreciação podem facilitar a produção de toda uma emocionalidade destrutiva que promove a ruptura com as perspectivas futuras, o engajamento em formas de tratamento equivocadas e arriscadas, a alimentação de sistemas de crenças nocivos para a concepção da dor, o isolamento social e até concepções punitivas de caráter religioso ou filosófico.

Desse modo, as formas de sugestôes ilustradas no caso do sr. Severino visaram, por meio de uma forma peculiar de argumentação, promovem a reconfiguração de importantes núcleos de sua subjetividade. Um deles era ligado à sua autoimagem (Gallagher \& Zahavi, 2008), altamente perpassada pela vergonha de suas origens culturais, enquanto o outro, muito integrado ao primeiro, a suas formas dominantes de se relacionar com os outros, nas quais comumente se colocava numa condição inferior a ser explorado e prejudicado fosse em termos emocionais, fosse em termos materiais e financeiros. Contudo, em vez de se propor uma simples argumentação, buscando convencê-lo racionalmente da incoerência de suas concepções atuais, procurou-se mostrar, por meio das sugestôes construídas com base nos argumentos por ele mesmo utilizados, que havia uma forte relação entre o menino sabido do sertão e o empresário bemsucedido da atualidade. A descrição minuciosa dos feitos do menino foi seguida do encontro interativo entre ambos, da sugestão na qual "como é difícil entender que homens eminentes foram crianças um dia" e de uma dissociação em que 
uma parte dele poderia pensar em sua situação atual enquanto a outra poderia se concentrar nas imagens da feira de sua infância.

Essa forma de argumentação pode ser mais precisamente compreendida como se segue. Cada momento dessas sugestóes entre aspas evocou uma série de possíveis interpretantes simbólicos junto ao paciente, por exemplo: "E fico me perguntando como será que aquele menino pobre, na Paraíba, conhecia tanto de cabras, vacas, cavalos [...] sabia como eram, do que precisavam [...] como cuidar deles [...] e era um bom negociador [...] sabia vender, trocar [...] fazer boas trocas pra sua família na feira" - interpretante evocado - você foi uma criança muito inteligente, essa inteligência está em você, nas suas raizes; "e se você visse esse menino agora, fico me perguntando o que você diria pra ele [...] e que conselhos você gostaria de dar pra ele" - você pode acessar esse saber, influenciálo; você pode reconhecer esse menino, ele está próximo, acessivel a você; "e também fico me perguntando sobre como pode um grande homem ter sido um dia um menino [...] esperto, arteiro, [...] às vezes pode parecer difícil entender como homens eminentes podem ter sido crianças um dia [...]" - homens eminentes foram crianças um dia, você é um homem eminente; e você pode pensar sobre isso; pensar sobre como você foi uma criança inteligente e se tornou um homem inteligente; estar lá e aqui, vendo que relaçôes existem entre seu passado e seu presente. O que fica em questão nesse grupo de sugestões não é apenas a sequência entre elas, mas a dimensão do símbolo (Peirce, 1998a) que passa a representar as relações entre elas em termos de mediação, de conceber uma generalidade que as ligue relacionando o presente bem-sucedido e o passado, agora visto na riqueza de suas raízes culturais e pessoais. Isso abriu o espaço para que o paciente reconhecesse o valor de suas origens, feitos e conquistas, de maneira a estabelecer, de modo relativamente rápido, importantes modificações nas configurações subjetivas sobre si mesmo e as relações com os outros, nas quais a valorização de si mesmo e de suas necessidades, antes negligenciadas pelo próprio paciente, passaram a entrar como elemento central.

\section{CONSIDERAÇÕES FINAIS}

Tais reflexões trazem à tona a possibilidade de se conceberem algumas ideias iniciais que permitam uma aproximação inicial entre as sugestôes hipnóticas e a experiência de pessoas com dores crônicas. A primeira delas é a de que, devido à diversidade de signos presente numa sugestão, não existe uma linearidade entre elas e os processos configuracionais que se desencadeiam num itinerário terapêutico. Contudo é possível conceber que haja uma dominância, uma ênfase maior em um determinado nível e mesmo em núcleos específicos de suas 
respectivas configurações. Essa dominância mostra uma correspondência entre a lógica presente nas sugestôes (por exemplo, simbólica) e o tipo de interpretantes evocados, que se caracterizam aqui por produções subjetivas e vividas que emergem dos sistemas de configuraçôes. Assim, mesmo que uma sequência de sugestões traga vários signos (como as frases, alterações de tom de voz, cadência, modificações na coreografia corporal, expressões faciais), elas têm uma lógica dominante que é capaz de se endereçar preferencialmente a determinados níveis em que se configuram certas vivências de dores crônicas.

Assim, enquanto no caso do sr. José Antônio as sugestôes, ressaltando uma dominância dos índices, acabam por evocar fortes experiências sensórias e nítidas reações fisiológicas ("secundidade"); no caso do sr. Severino, a ênfase das sugestôes, caracterizadas por uma hegemonia do simbólico ("terceiridade"), desencadeia processos de reconstrução narrativa a respeito de si mesmo. Assim, embora seja possível conceber que, em ambos os casos, haja uma profusão considerável de diferentes signos nas sugestôes, há um direcionamento a núcleos mais específicos de configurações de dores crônicas de cada uma dessas pessoas que ali se apresentavam como demandas clínicas da mais alta relevância. Esse direcionamento é fundamental em semelhantes processos, uma vez que atende a necessidades clínicas centrais das pessoas que, muitas vezes, podem não ser contempladas quando o tratamento se restringe a uma questão física (como os procedimentos médicos) ou simbólica (como em boa parte das psicoterapias). Desse modo, mesmo que uma pessoa tenha maior facilidade para se fixar em um nível específico, como o vital com toda sua sensorialidade, caso não haja tal direcionamento, tais demandas podem ficar sem ser devidamente trabalhadas em seu processo terapêutico.

Tais colocações remetem a uma segunda questão que deve ocupar um lugar central nesta concepção: a necessidade de uma concepção ampla de subjetividade (Rey, 2011; Neubern, 2014). Isso porque as necessidades do sujeito, a dominância semiótica das sugestões e os processos de reconfiguração da experiência devem ser pensados tomando-se o cenário do sujeito como princípio, e não como variáveis a serem isoladas e compreendidas sob uma metáfora computacional distante dos processos humanos. Dito de outro modo, as experiências da pessoa, assim como todas as trocas semióticas do processo relacional, devem ser concebidas em sua singularidade, como processos vividos e simbólicos daquela pessoa. Não há, portanto, uma sensação em si de queimadura, mas um signo (índice) que se integra a complexos sistemas configuracionais que compóem uma totalidade da experiência da pessoa e que tem uma qualidade específica nesse conjunto, uma qualidade única e irrepetível que pode ou não se relacionar com os processos simbólicos. Essa complexa rede de processos remete a um conjunto de noções- 
chave em termos de produção de conhecimento, como a qualidade, o sujeito, a interpretação na construção das informações, o valor heurístico destas, a reflexividade sobre o contexto e a própria subjetividade do pesquisador (Rey, 2005).

Outro fragmento merecedor de atenção no tocante a essa relação entre sugestōes hipnóticas e níveis de experiência é o problema da autonomia (Morin, 2005). Seria possível considerar a proximidade dessa reflexão com questôes que inquietam os clínicos da hipnose na dor crônica (Brugnoli, 2014; CelestinLhopiteau, 2011), que sustentam que, para que o processo terapêutico e hipnótico seja bem-sucedido, o paciente precisa assumir seu papel de sujeito, tornando-se protagonista nesse processo, mesmo que em transe. No entanto, se o transe se caracteriza por uma série de processos inconscientes e involuntários, fica aberta a lacuna sobre em que consiste essa tomada de papel ativo no processo hipnótico e qual o papel das sugestôes e seus signos nesse processo. Nos casos aqui discutidos, como o do sr José Antônio, as sensações de calor e as fortes emoções da experiência de transe coincidem com uma reorganização da experiência em termos vitais que parece remeter a uma dimensão criativa, involuntária e inconsciente do sistema capaz de produzir mudanças em suas possibilidades de organização de postura e movimento. Os signos de autonomia próximos a uma lógica de agenciamento (Gallagher, 2012) nesse nível não podem ser compreendidos em termos de uma deliberação racional, mas possivelmente ligados às noçôes típicas da dimensão vital como regulação, preservação, redução da perturbação, entropia da dinâmica energética e diminuição da influência dolorosa no tocante à auto-organização de tais sistemas (Merleau-Ponty, 2005; Morin, 2001). Assim, concebe-se que, possivelmente, o uso de sugestões com ênfase em ícones e índices pode favorecer uma espécie de comunicação com tal nível de agenciamento, uma espécie de interação que não privilegia o diálogo racional, mas possibilita uma influência mútua fundamentada em pautas de trocas energéticas e emocionais das quais o sujeito geralmente não tem consciência nem tem controle. É possível que seja nesse ponto que, de acordo com o trabalho dos clínicos (Erickson \& Rossi, 1979; Roustang, 2006), conceba-se a existência de toda uma dimensão vivida e involuntária da experiência além dos limites do eu que não pode ser controlada nem acessada de forma linear, mas com a qual é possível se aliar para o desencadeamento de recursos terapêuticos de grande valia para o processo. Ficam, entretanto, as indagaçôes em torno do que seria essa dimensão, como ela agiria na regulação dos processos fisiológicos e quais relações teria com os diferentes circuitos que compóem os processos do adoecimento e da cura na relação com a hipnose. 
De modo igualmente curioso, as ideias parciais que passaram a emergir a partir das sugestôes no caso do sr. Severino foram decisivas para que pudesse modificar uma série de configuraçôes de sentido a respeito de si mesmo, como se uma outra dimensão de sua psique soprasse sutilmente (e não de forma doutrinária) a seu eu novas maneiras de compreender suas origens e o impacto delas em sua vida atual. Semelhante processo, no qual se pode destacar a primazia dos simbolos (mas sem a exclusão de ícones e índices), também implica uma dimensão inconsciente, mas pensante, que deve ser concebida em sua autonomia e potencial criativo, pois não se situa sob os domínios do eu racional. Isso deve implicar, na construção das sugestões, o reconhecimento de que há uma dimensão subjetiva além do pensar deliberado que tem sabedoria e capacidade própria de agenciamento, com a qual o sujeito pode desenvolver um diálogo interno de grande relevância para suas demandas clínicas. Cabe aqui, novamente, a mesma advertência segundo a qual tal dimensão não consiste num campo de domínio do $e$, de maneira que o uso dos simbolos não deve primar pelas tentativas unívocas de controle, que facilmente poderiam colocar em risco o processo terapêutico. No entanto o campo da pesquisa ainda se mantém aqui rico de indagaçõos e lacunas, uma vez que pouco se sabe sobre semelhante dimensão do inconsciente. Se seriam elas vozes internas, instâncias sábias da psique, desdobramentos da personalidade, tal como as possibilidades teóricas exploradas ao longo da história (Michaux, 2007), são questôes que apenas o refino conceitual aliado ao rigor metodológico da pesquisa clínica poderão responder. 


\section{REFERÊNCIAS}

Abrahamsen, R., Baad-Hansen, L., Zachariae, R. \& Svensson, P. (2011). Effect of hypnosis on pain and blink reflexes in patients with painful temporomandibular disorders. The Clinical Journal of Pain, 27(4), 344-351.

Breton, D. (2012). Expériences de la douleur. Paris: Métailié.

Brugnoli, M. P. (2014). Clinical hypnosis in pain therapy and paliative care. Illinois: C. H. Thomas.

Célestin-Lhopiteau, I. (2011). Changer par la thérapie: du chamane au psychothérapeute. Paris: Dunod.

Cyrulnik, B. (2001). Les vilains petits canards. Paris: Odile Jacob.

Dillworth, T. \& Jensen, M. (2010). The role of sugestions in hypnosis for chronic pain: a review of the literature. Open Pain, 3(1), 39-51.

Erickson, M. (1983). An introduction to the study and application of hypnosis in pain control. In M. Erickson. (Org.), Healing in hypnosis. (pp. 217-277). New York: Irvington.

Erickson, M. \& Rossi, E. (1979). Hypnotherapy: an exploratory casebook. New York: Irvington.

Gallagher, S. (2012). Multiple aspects of agency. New Ideas in Psychology, 30, $15-31$.

Gallagher, S. \& Zahavi, D. (2008). The phenomenological mind. New York: Routledge.

Goldstein, R. (2011). Hypnosis and pain: no longer an "Alternative". Clinical Journal of Pain, 27(4), 375-376.

Jensen, M. (2010). A neuropsychological model of pain: research and clinical implications. The Journal of Pain, Chicago, 11(1), 2-12.

Jensen, M. \& Patterson, D. (2014). Hypnotic approaches for chronic pain management. American Psychologist, 2, 167-177.

Johnson, M. (2007). The meaning of the body. Chicago: CUP.

Kirjanen, S. (2012). Brain actitivy during pain relief using hypnosis and placebo treatments. Journal of European Psychology Students, 3, 78-87. 
Merleau-Ponty, M. (2005). La structure du comportement. Paris: Puf.

Merleau-Ponty, M. (2008). La phénoménologie de la perception. Paris: Gallimard.

Michaux, D. (2007). Douleur et hypnose. Paris: Imago.

Morin, E. (2001). La méthode V. L'humanité de l'humanité. Paris: Seuil.

Morin, E. (2005). La méthode VI. L'Ethic. Paris: Seuil.

Neubern, M. (2010). Psicoterapia, dor e complexidade: construindo o contexto terapêutico. Psicologia: Teoria \& Pesquisa, 26(3), 99-107.

Neubern, M. (2012). Técnicas hipnóticas, dores crônicas e a emergência do sujeito. Gerais: Revista Interinstitucional de Psicologia, 5(2), 317-333.

Neubern, M. (2013). Hipnose, dores crônicas e técnicas de ancoragem. A terapia de dentro para fora. Psicologia: teoria \& pesquisa, 29(3), 297-304.

Neubern, M. (2014). Subjetividade e complexidade na clínica psicológica: superando dicotomias. Fractal, Revista de Psicologia, 3(26), 835-852.

Peirce, C. S. (1998a). The categories defended. In N. Houser (Org), The essential Peirce. Selected philosophical writtings. (pp. 160-178). Bloomington: Indiana University Press. (Texto original publicado em 1903).

Peirce, C. S. (1998b). What is a sign? In N. Houser (Org), The essential Peirce: selected philosophical writtings. (pp. 4-10). Bloomington: Indiana University Press. (Texto original publicado em 1894).

Portaria $n^{o} 1.083$ (2012, 2 de outubro). Aprova protocolo clínico e diretrizes terapêuticas para a dor crônica. Diário Oficial da União, Brasília.

Rey, F. G. (2005). Pesquisa qualitativa e subjetividade. São Paulo: Thomsom.

Rey, F. G. (2011). Subjetividade e saúde: superando a clínica da patologia. São Paulo: Cortez.

Roustang, F. (2006). Savoir attendre pour que la vie change. Paris: Odile Jacob.

Stern, D. (2010). Forms of vitality. London: Oxford University Press.

Teeley, A., Soltani, M., Wiechman, S., Jensen, M., Sharar, S. \& Patterson, D. (2012). Virtual reality hypnosis pain control in the treatment of multiple fractures: a case series. American journal of clinical hypnosis, 54(3), 274-290. 
Vaitl, D. (2010). Altered states of consciousness: brain dynamics and pain processing during hypnosis and meditation. International Journal of Psychopathology, 77, 216-217.

World Health Organisation (2014). World Health Organisation supports global efforts to relieve chronical pain. Geneva: WHO, 2004. Recuperado a partir de www.who.int/mediacentre/news/releases/2004/pr70/en/. 